\title{
System Realization of CASHIPS DC High Power Test Facility
}

\author{
Xiaojiao Chen, Liansheng Huang, Peng Fu, Ge Gao, Zhiquan Song, Liuwei Xu, Shiying He, \\ and Xiuqing Zhang
}

\begin{abstract}
Aims to complete the test of the International Thermonuclear Experimental Reactor (ITER) poloidal field (PF) converter system, and to meet future continuous upgrading needs of a modern industrial power system and scientific research, direct current (DC) high-power test facility of Hefei Institutes from Physics science, Chinese Academy of Sciences (CASHIPS) is built in 2011. As the largest DC high-power test facility in China, the rated steady state DC current is $120 \mathrm{kA}$ and the pulse peak current is $500 \mathrm{kA}$. Four thyristor-based AC/DC converter modules are paralleled to handle this huge current. In May 2017, 15 testing items are accredited by the China National Accreditation Service (CNAS) for Conformity Assessment . Up to now, the test for 17 devices of 16 companies and manufacturers in the world have been completed. In this paper, the topology and the control of DC High-Power test facility are presented. In addition, the testing capability and the completed tests of DC high-power test facility are illustrated.
\end{abstract}

Index Terms-120 kA steady state DC current, $500 \mathrm{kA}$ pulse peak current, DC high-power test facility.

\section{INTRODUCTION}

$\mathrm{W}$ ITH the development of modern industrial power systems, scientific research, the capacity of the high-power electrical equipment test facility is expanded and upgraded continuously to satisfy the needs of economic and social development. At present, there are more than 10 well-known power labs with DC high-power test facility all over the world. Most of the leading electric companies have their own high-power labs, in addition to some independent high-power laboratory. According to the investigation, the biggest DC testing voltage is $7 \mathrm{kV}$ and the largest DC testing current is up to $320 \mathrm{kA}$ before 2011 [1].

International Thermonuclear Experimental Reactor (ITER) is an international collaboration project located in south France to demonstrate the scientific and technological feasibility of fusion energy for peaceful purposes [2], [3]. The ITER poloidal field (PF) AC/DC converter system mainly provides the controlled current thereby implementing the plasma shape and position control, which is one of the key systems for ITER [4], [5].

Manuscript received January 4, 2019. This paper was presented in part at the 2018 IEEE International Power Electronics and Application Conference and Exposition (PEAC), Shenzhen, China, November 2018. (Corresponding author: Liansheng Huang.)

X. Chen, S. He, and X. Zhang are with the Institute of Plasma Physics, Chinese Academy of Sciences, Hefei, China.

L. Huang, P. Fu, G. Gao, and L. Xu are with the Institute of Plasma Physics, Chinese Academy of Sciences and the University of Science and Technology of China, Hefei, China (e-mail: huangls@ipp.ac.cn).

Z. Song is with ITER Organization, Route de Vinon-sur-Verdon, France.

Digital Object Identifier 10.24295/CPSSTPEA.2019.00010
The ITER PF AC/DC converter Procurement Arrangement (PA) was signed between China Domestic Agency (DA) and ITER Organization (IO) in April 2011. The Institute of Plasma Physics, Chinese Academy of Science (ASIPP) takes the responsibility of ITER PF AC/DC converter PA. The PF AC/ $\mathrm{DC}$ converter system is a major $\mathrm{AC} / \mathrm{DC}$ converter system, and the total installation power is $1.2 \mathrm{GVA}$. The ITER PF AC/DC converter system required DC short-circuit impulse test current is $400 \mathrm{kA}$ and the DC steady state testing current is up to $100 \mathrm{kA}$ for type test [6]. Hence, the existing test facilities cannot satisfy the test requirements of the ITER PF AC/DC converter system.

Considering the testing requirements of ITER PF AC/DC converter system components and continuous upgrading capacity of high-power test capability, the steady-state current of DC high-power test facility is rated at $120 \mathrm{kA}$ and the pulse current is $500 \mathrm{kA} .120 \mathrm{kA}$ steady-state current make it the largest steady state DC current test facility in China until now. The DC high-power test facility of Hefei Institutes of Physics science, Chinese Academy of Sciences (CASHIPS) is a professional test facility. 15 testing items are accredited by the China National Accreditation Service (CNAS) for Conformity Assessment in May 2017. The relevant reports are accredited by 35 countries including France, Germany, Italy, United Kingdom, United States, etc.

Designed and constructed by ASIPP, co-phase counter parallel connection topology structure is selected on account of the low voltage and the high current of DC high power test facility. In this paper, the characters, parameters and operation modes of DC high power test facility are presented. In addition, the configuration of the control system, hardware and software of the local controller is illustrated in detail. Moreover, the relevant qualification experiments including the testing capability and some completed tests are also provided. The paper is organized as follows. The topology and the control of DC high-power test facility is presented in Section II and Section III respectively. The qualification experiments are performed in Section IV. In this part, the experiment of $120 \mathrm{kA}$ rated steady state DC current and $500 \mathrm{kA}$ pulse current is carried out to demonstrate the testing capabilities. Moreover, some typically completed tests are also provided in this part. At last, the conclusion is drawn in Section V.

\section{Topology of the DC High-Power Test Facility}

\section{A. Topology Structure}

Four AC/DC converter modules are paralleled to handle 


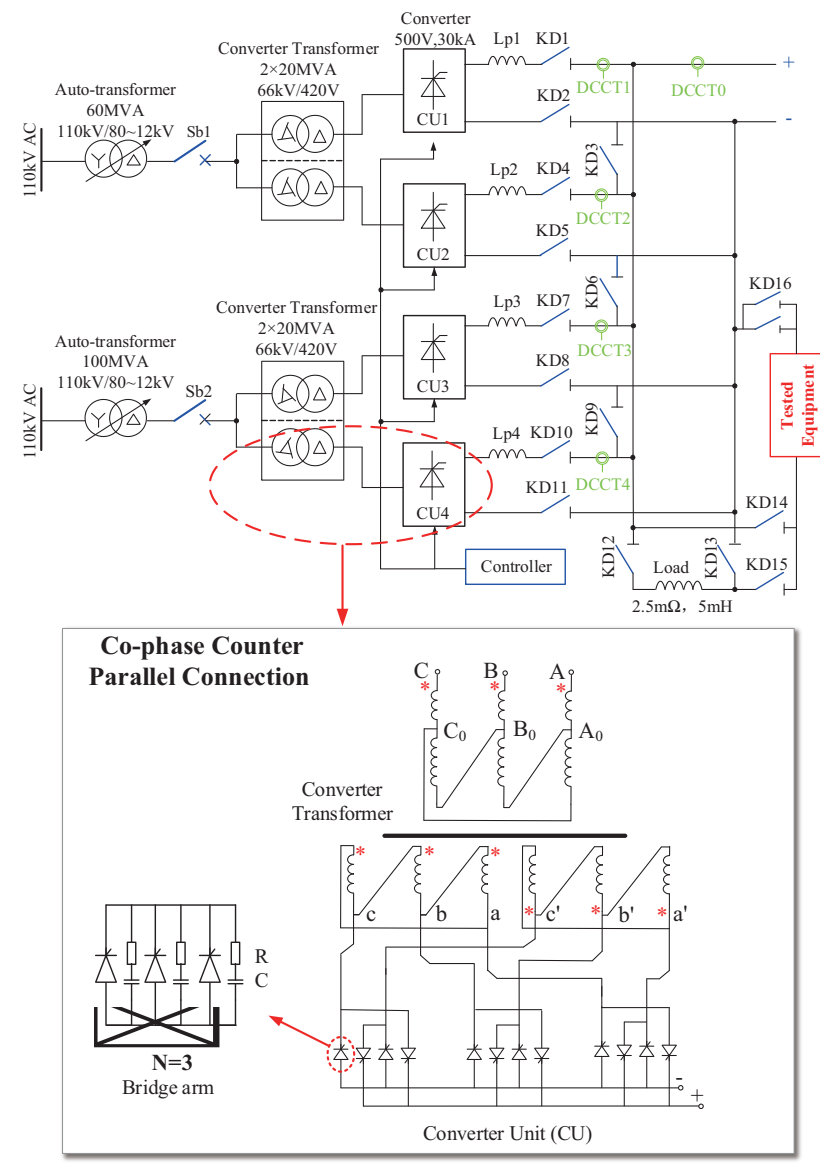

Fig. 1. DC high-power test facility scheme.

$120 \mathrm{kA}$ steady-state DC current and $500 \mathrm{kA}$ pulse current. $30 \mathrm{kA}$ rated steady-state $\mathrm{DC}$ current and $0.5 \mathrm{kV}$ rated $\mathrm{DC}$ voltage of each converter module make the co-phase counter parallel connection topology structure the suitable choice for DC high power test facility as Fig. 1. Co-phase counter parallel connection topology structure not only reduces the current carrying load of transformer individual windings, but also reduces the eddy power loss and heat generation of the transformer because the adjacent two-phase windings currents are reversed. In addition, the magnetic flux density in the converter cabinet is near to zero, which improve the operating environment of the semiconductor component [7].

IGBT, IGCT and other semiconductor is wildly studied and used in high power electronic field [8], [9], [10]. However, with the outstanding advantages that heavy current, high voltage, relatively small heat dissipation density and low cost, the thyristor-based $\mathrm{AC} / \mathrm{DC}$ converter module is chosen and each bridge arm is paralleled with 3 thyristors and RC snubber circuit. The type of thyristor is ABB 5STP $50 \mathrm{Q} 1800$.

As shown in Fig. 1, the DC high-power test facility is composed by 110/66 kV 100 MVA and 115/66 kV 60 MVA autotransformers, four 20 MVA converter transformers, four $30 \mathrm{kA} / 0.5 \mathrm{kV}$ converters, four DC reactors $(50 \mathrm{uH})$, load $(2.5 \mathrm{~m} \Omega, 5 \mathrm{mH})$ and sixteen DC disconnectors. Each

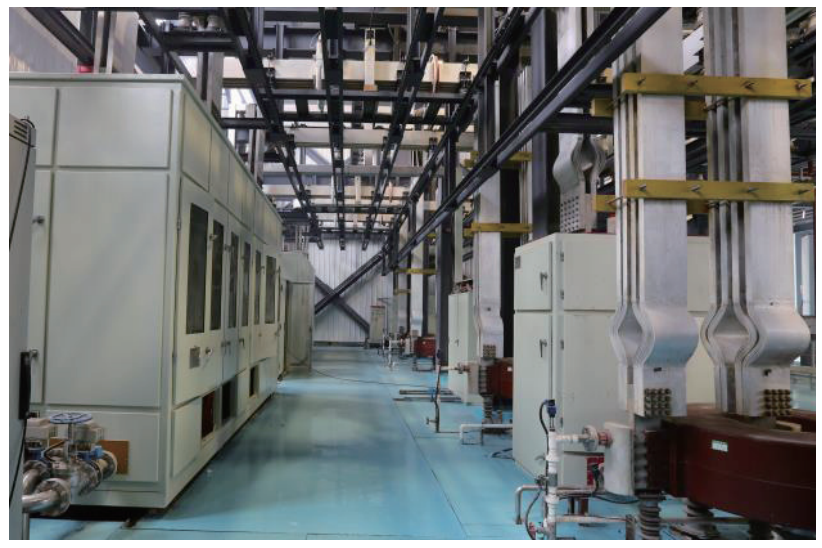

Fig. 2. DC high-power test facility.

TABLE I

Operation Modes

\begin{tabular}{lcc}
\hline \hline Operation Mode & Operation Converter Module & Parameter \\
\hline $\begin{array}{l}\text { Single converter } \\
\text { operating }\end{array}$ & $\mathrm{CU} 1 / \mathrm{CU} 2 / \mathrm{CU} 3$ / CU4 & $30 \mathrm{kA}$, \\
& & $0.5 \mathrm{kV}$ \\
$\begin{array}{l}\text { Two converters in } \\
\text { parallel }\end{array}$ & $\mathrm{CU} 1 \& \mathrm{CU} 2 / \mathrm{CU} 3 \& \mathrm{CU} 4$ & $60 \mathrm{kA}$, \\
& & $0.5 \mathrm{kV}$ \\
Four converters & $\mathrm{CU} 1 \& \mathrm{CU} 2 \& \mathrm{CU} 3 \& \mathrm{CU} 4$ & $120 \mathrm{kA}$, \\
in parallel & & $0.5 \mathrm{kV}$ \\
& & $30 \mathrm{kA}$, \\
$\begin{array}{l}\text { Two converters } \\
\text { in series }\end{array}$ & $\mathrm{CU} 1 \& \mathrm{CU} 2 / \mathrm{CU} 3 \& \mathrm{CU} 4$ & $1.0 \mathrm{kV}$ \\
& & $30 \mathrm{kA}$, \\
Four converters & $\mathrm{CU} 1 \& \mathrm{CU} 2 \& \mathrm{CU} 3 \& \mathrm{CU} 4$ & $2.0 \mathrm{kV}$ \\
\hline in series & & \\
\hline \hline
\end{tabular}

thyristor-based $\mathrm{AC} / \mathrm{DC}$ converter module is connected to a converter transformer. The converter transformers are phase shifting to each other in order to implement the 24 pulses output in DC terminal thereby eliminating harmonics at specific frequencies on the $\mathrm{AC}$ side and reducing current ripple in DC side. The DC high-power test facility scheme and parameters are shown as Fig. 1 [11]. CU1-CU4 are the four AC/DC converter modules, KD1-KD16 are the DC disconnectors, Lp1-Lp4 are the DC reactors, DCCT0DCCT4 are the current sensors [12]. The DC high-power test facility is shown as Fig. 2.

\section{B. Operation Modes}

The converters can operate in different operation modes to satisfy the different test requirements. As shown in Table I, the operating modes include single converter operating mode, converters in parallel operating mode, and converters in series operating mode. DC disconnector array is designed to change the circuit connection to implement multiple operating modes according to the different test requirements. The autotransformers are set in different position according to the required maximum voltage and 


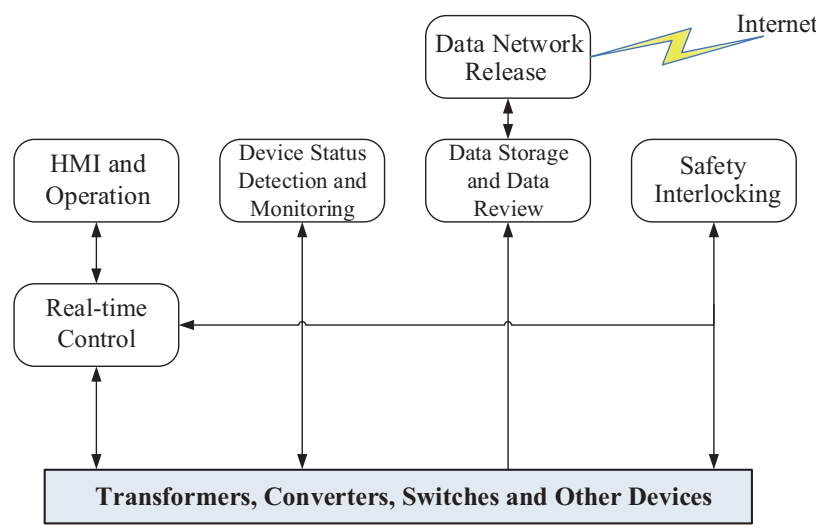

Fig. 3. The structure of the control system.

current ripple, and which is helpful to reduce the current ripple in some case.

\section{The Control System of DC High-Power Test FACILITY}

\section{A. The Configuration of Control System}

The test facility control system is divided into the following different parts according to the functions: human machine interface (HMI) and operation, real-time control, device status detection and monitoring, data storage and data review, data network release, and interlock. The structure of the control system is shown in Fig. 3.

- HMI and operation: to set the operation parameters such as waveform preset, converter operation mode, converter control mode, and to operate the converter state machine.

- Real-time control: to complete voltage open-loop and current closed-loop control operation, and to change the operation mode in real time according to the rectifier operating parameters, and to act the interlock action.

- Device status detection and monitoring: to detect the status of transformers, rectifiers and switchgears periodically, and to monitor the status. And to act the remote operation of switches.

- Data storage and data review: to measure the circuit voltage, current of transformer and converters. To store the data and review the data.

- Safety interlock: to act the occupation safety function.

Each part of the control system is interconnected through the network. According to the different performance and function requirements, the control network is divided into two types: shared memory real-time network and Ethernet. Each network is independent, and all devices are in the same network layer to ensure data transmission efficiency. As the core controller of the DC high-power test facility, the real-time controller is also called the local controller.

\section{B. The Local Controller}

The local controller is based on Compact PCI computer [13],

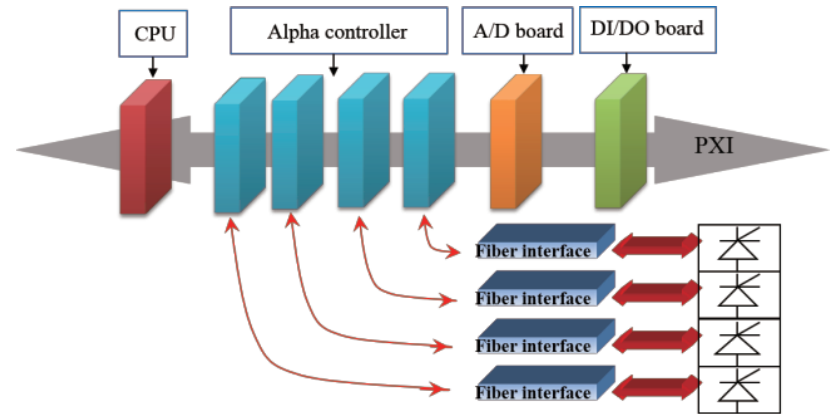

Fig. 4. The configuration of loacl controller.

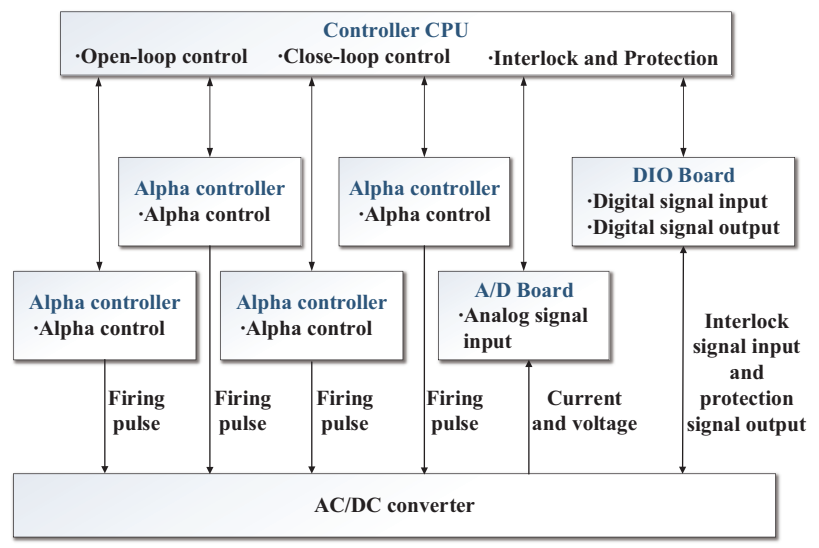

Fig. 5. The control block of local controller.

and the Compact PCI chassis is 12V18OPX98Y5VQ2X/ ELMA; According to the real-time reference voltage, the trigger angle is calculated by CPU and the CPU board type is CP6005; Then, the converter bridge control and the trigger pulses generating is implemented by the alpha controller. Alpha controller outputs and modulates the trigger signal into a $15 \mathrm{kHz}$ pulse to reduce the amplifier power and send the trigger pulse at the corresponding time to the thyristors by optical fiber, and the alpha controller type is CPCI-2008. Each converter module is controlled by an independent alpha controller. The configuration of the local controller is shown in Fig. 4. The AD board type is CPCI-9116 for analog signal input and the DIO board type is CPCI-7432 for digital signal input and output. The control block of local controller is shown in Fig. 5.

Fig. 6 shows the cubicle configuration of the local controller. The synchronization board is used to obtain the synchronization signal. The synchronization signal is delivered to the local controller to provide an accurate phase synchronization and frequency synchronization for the trigger time. The feedback signal and protection signal is collected by fast $\mathrm{A} / \mathrm{D}$.

\section{Testing CApabiLITy}

\section{A. 120 kA Steady State DC Current}

The DC test facility is composed of four $30 \mathrm{kA} / 0.5 \mathrm{kV}$ 


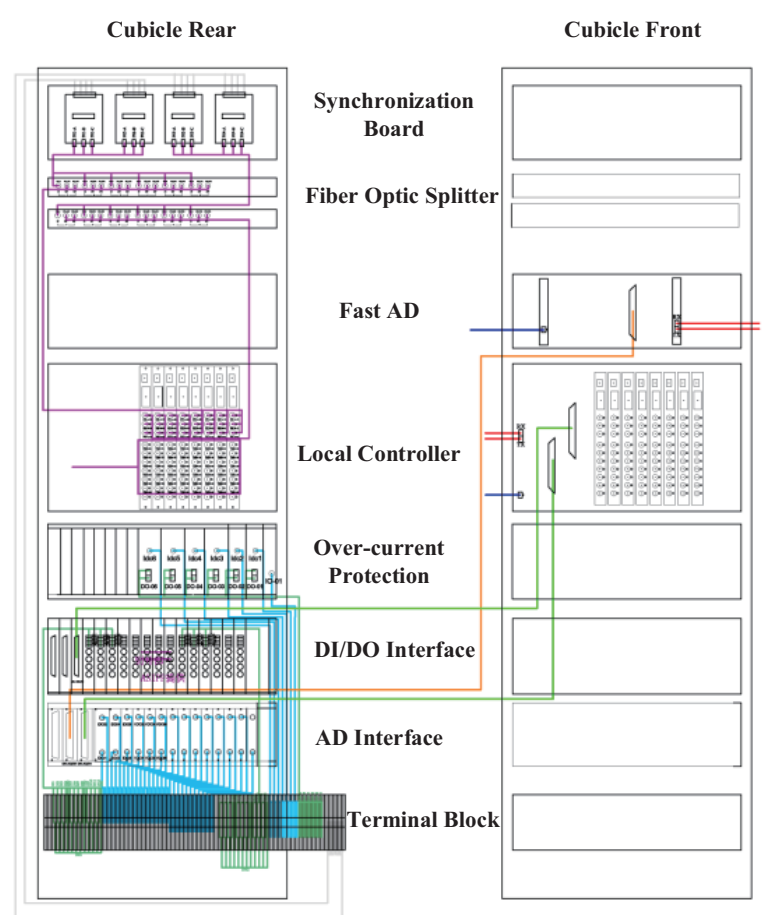

Fig. 6. The cubicle configuration of local controller.

converters. These converters could be operated in different modes to implement different required output. The output performance of different operation mode is shown in Table II.

When the four converter modules are in parallel, the steady state output current is rated to $120 \mathrm{kA}$. The huge DC continues current could be outputted to implement superconducting coil test, high temperature current lead test, DC disconnect test, etc. During steady state operation, the current closed loop control is adopted. The typical experiment results that rated current of $120 \mathrm{kA}$ is shown as Fig. 7.

\section{B. 500 kA Pulse Current}

1) The Output Capability Calculation Based on System Parameters

Based on the analysis of the system parameters, the pulse current test capability of DC test platform is calculated. The equivalent circuit of four paralleled converter units is shown in Fig. 8. The $U_{\mathrm{d} 0}$ is the no-load voltage of the converter; $R_{\mathrm{S} 4}$ is the internal resistance of the four paralleled converter units; $L_{\mathrm{p}}$ is the inductance of DC reactor; $L_{\mathrm{d}}$ is the inductance of DC circuit; $R_{\mathrm{d}}$ is the DC resistance; $R_{1}$ is the resistance of the stainless steel resistor.

According to Fig. 8, the (1) can be obtained as:

$$
\left\{\begin{array}{l}
U_{\mathrm{d} 0}-R_{\mathrm{S} 4} i_{\mathrm{d}}-\frac{L_{\mathrm{p}}}{4} \times \frac{\mathrm{d} i_{\mathrm{d}}}{\mathrm{d} t}=\left(R_{\mathrm{d}}+R_{1}\right) i_{\mathrm{d}}+L_{\mathrm{d}} \frac{\mathrm{d} i_{\mathrm{d}}}{\mathrm{d} t} \\
U_{\mathrm{d} 0}=1.35 U_{2} \cos \alpha
\end{array}\right.
$$

TABLE II

Operation Parameters of DC High-Power Test Facility

\begin{tabular}{cccc}
\hline \hline Operation Mode & Parameter & Value & Ripple \\
\hline \multirow{2}{*}{ Single converter operating } & Rated DC voltage & $500 \mathrm{~V}$ & - \\
& Rated DC current & $30 \mathrm{kA}$ & $\leqslant 1 \%$ \\
\hline \multirow{2}{*}{ Two converters in parallel } & Rated DC voltage & $500 \mathrm{~V}$ & - \\
& Rated DC current & $60 \mathrm{kA}$ & $\leqslant 1 \%$ \\
\hline \multirow{2}{*}{ Four converters in parallel } & Rated DC voltage & $500 \mathrm{~V}$ & - \\
& Rated DC current & $120 \mathrm{kA}$ & $\leqslant 1 \%$ \\
& Short pulse current & $500 \mathrm{kA}$ & - \\
\hline \multirow{2}{*}{ Two converters in series } & Rated DC voltage & $1.0 \mathrm{kV}$ & - \\
& Rated DC current & $30 \mathrm{kA}$ & - \\
\hline \multirow{2}{*}{ Four converters in series } & Rated DC voltage & $2.0 \mathrm{kV}$ & - \\
& Rated DC current & $30 \mathrm{kA}$ & - \\
\hline \hline
\end{tabular}

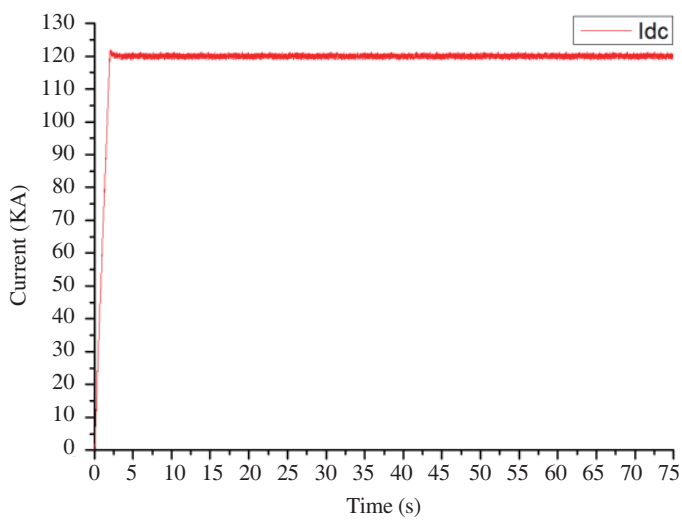

Fig. 7. The $120 \mathrm{kA}$ steady state current profile ( $I_{\mathrm{dc}}$ is the de terminal current).

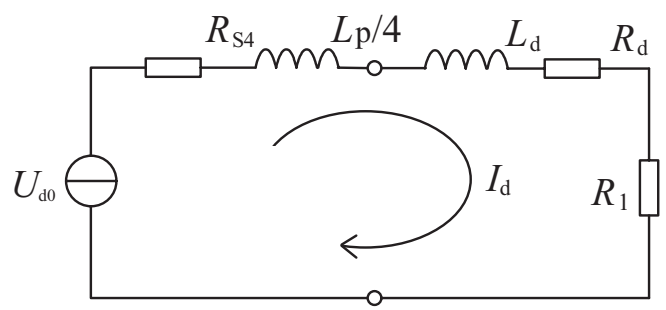

Fig. 8. The equivalent circuit of four paralleled converter units.

The $U_{2}$ is the secondary phase to phase voltage of the converter transformer. Then (1) can be equivalent to (2).

$$
\left(R_{\mathrm{S} 4}+R_{\mathrm{d}}+R_{1}\right) i_{\mathrm{d}}+\left(L_{\mathrm{d}}+\frac{L_{\mathrm{p}}}{4}\right) \frac{\mathrm{d} i_{\mathrm{d}}}{\mathrm{d} t}=1.35 U_{2} \cos \alpha
$$

The $I_{\mathrm{d}}$ can be calculated:

$$
\begin{gathered}
I_{\mathrm{d}}=\frac{1.35 U_{2} \cos \alpha}{R_{\mathrm{S} 4}+R_{\mathrm{d}}+R_{1}}\left(1-e^{-t / \tau_{4}}\right) \\
\tau=\frac{L_{\mathrm{d}}+L_{\mathrm{p}} / 4}{R_{\mathrm{d}}+R_{1}+R_{\mathrm{S} 4}}
\end{gathered}
$$

Different transformer tap position corresponds to the 
TABLE III

Output Capability of Four Paralleled Converter Units

\begin{tabular}{cccccc}
\hline \hline & $U_{2}(\mathrm{~V})$ & $R_{\mathrm{S} 4}(\mathrm{~m} \Omega)$ & $R_{\Sigma}(\mathrm{m} \Omega)$ & $\tau(\mathrm{ms})$ & $I_{\mathrm{d}}{ }^{*}(\mathrm{kA})$ \\
\hline $115 / 80$ & 487 & 0.48 & 0.88 & 59.7 & 721.7 \\
$115 / 42$ & 256 & 0.27 & 0.67 & 78.4 & 498.3 \\
$115 / 12$ & 73 & 0.20 & 0.60 & 87.5 & 158.7 \\
\hline \hline
\end{tabular}

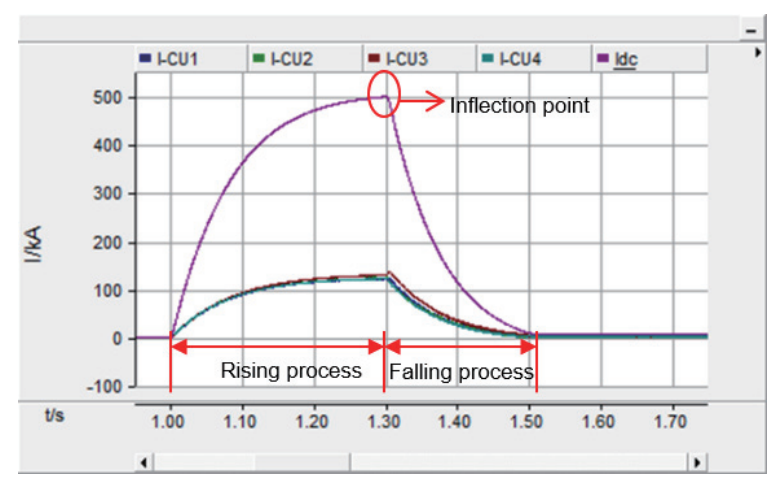

Fig. 9. The simulation of $500 \mathrm{kA}$ peak pulse current output.

different parameters. The internal resistance of the four paralleled converter units $R_{\mathrm{S} 4}$, the total resistance $R_{\Sigma}$, the (3) and (4) can be obtained as Table III.

The calculated output capability of the DC current in Table III is not the experiment current that the converter can withstand. The experiment peak current and its pulse width is limited by the thyristor limiting load integral parameter, the thyristor internal silicon temperature, and should be with some safety margins.

\section{2) The $500 \mathrm{kA}$ Output Capability Experiment}

For the pulse current operation, the whole process of the pulse can be divided into three stages, rising process, inflection point and falling process as Fig. 9. All of these three stages current control is required very fast dynamic response within milliseconds.

During the rising process, the converters work in the converter model. Because of the AC and DC loop impedance difference between each paralleled converter, the control purpose is not the same DC average voltage but the same current for each paralleled converter. During inflection point, it is, in fact, in a transient process, the converters should be changed from converter model to inverter model. Because of the phase shifting between each converter transformer, the DC voltage transient values of each converter is different, the DC output transient current is hard to be controlled. And any current overshoot could lead the converter failure because of the huge transient current. While during the falling process, the converters work in the inverter model. Because of the inherent characteristics commutation failure of thyristor-based converter when in inverter model, this process should be controlled carefully according to each converter DC current. And in this phase, the current sharing control is a very important task to make

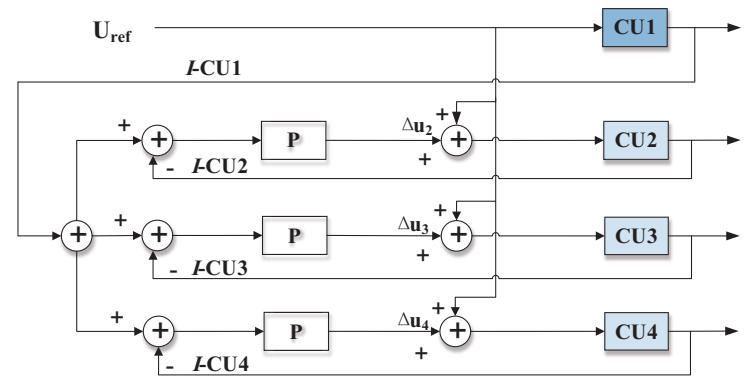

Fig. 10. Dynamic current sharing control strategy of $500 \mathrm{kA}$ pulse current. (I-CU1: CU1 converter current; I-CU2: CU2 converter current; I-CU3: CU3 converter current; $I$-CU4: CU4 converter current; $I_{\mathrm{dc}}$ : the de terminal current).

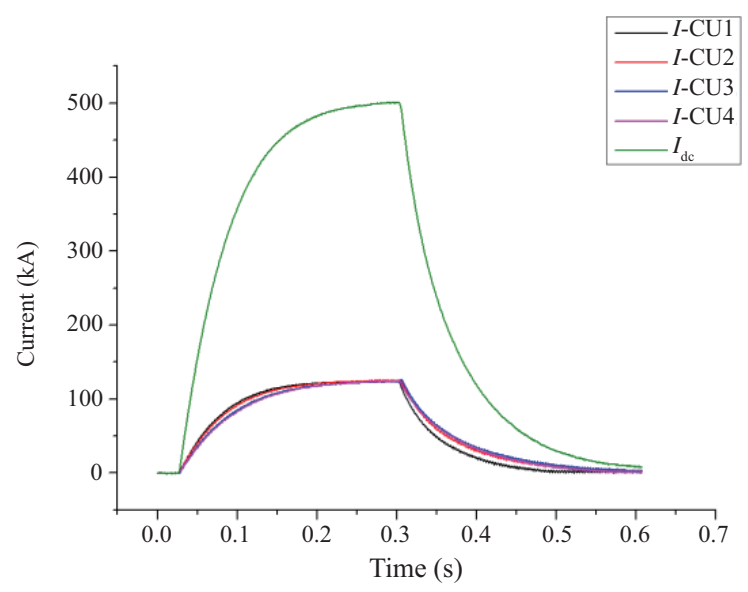

Fig. 11. The 500 kA Peak Pulse Current Profile (I-CU1: CU1 converter current; I-CU2: CU2 converter current; I-CU3: CU3 converter current; I-CU4: CU4 converter current; $I_{\mathrm{dc}}$ is the de terminal current).

sure the system safe.

As the key technology of DC high power test facility, the dynamic current sharing control strategy of $500 \mathrm{kA}$ pulse current is shown as Fig. 10.

The proportional control with the incremental control algorithm is adopted to ensure the dynamic characteristics and the system stability [14], [15]. $U_{\text {ref }}$ is the control reference voltage. The $P$ controller parameters are designed carefully to ensure the short response time, and to avoid overshoot or shock in operation. $\Delta u 1, \Delta u 2$ and $\Delta u 3$ are the incremental voltage.

With the characteristics that short pulse time, large output current and fast current rising, the voltage open loop and current closed loop are adopted for the pulse output operation. One of the paralleled converter CU1 is selected as the master module, and the other ones (CU2 to CU4) are treated as the slave modules, each slave module will perform current sharing adjustment according to the current of the master module $I$-CU1.

The experiment is carried out on DC high power test facility to verify the effectiveness and the feasibility of this control strategy. The $500 \mathrm{kA}$ pulse peak current output is shown as Fig. 11. In pulse operation, the output peak current is $500 \mathrm{kA}$ within $0.3 \mathrm{~s}$, the profile is shown in Fig. 11. These 


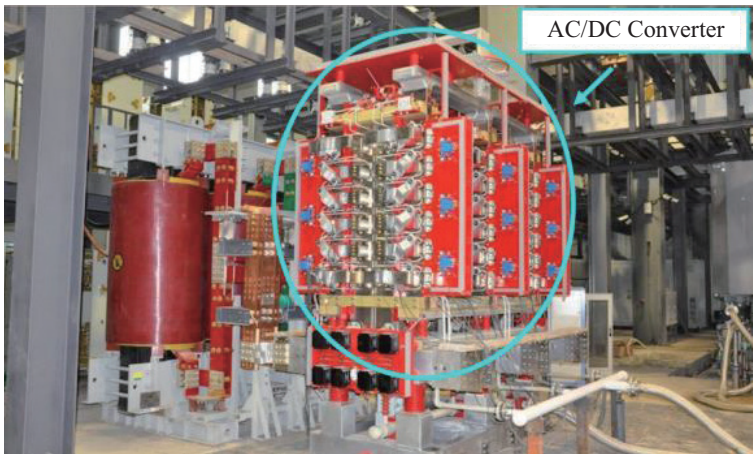

(a)

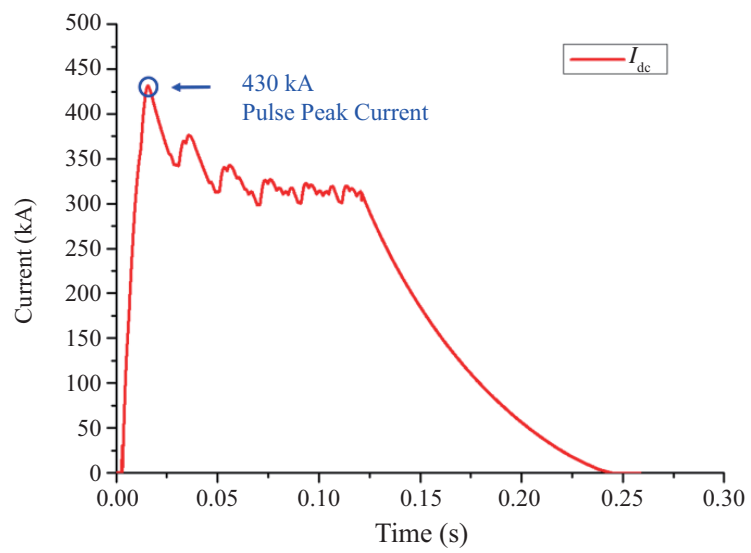

(b)

Fig. 12. AC/DC converter type test. (a) Test photo. (b) Test profile $\left(I_{\mathrm{dc}}\right.$ is the dc terminal current).

performance could be used for DC high-power equipment type test.

\section{The Completed Test}

Until now, 17 devices type test of 16 companies and manufacturers have been done, including $\mathrm{AC} / \mathrm{DC}$ converter type test, bypass the type test, DC reactor type test, feeder type test, DC line disconnector type test, and traction distribution DC switchgear type test, etc.

$\mathrm{AC} / \mathrm{DC}$ converter is implemented the type test, in order to verify the converter structural strength in case of the converter reactor upstream short. The thyristors were all replaced by high power diodes in order to achieve the peak current without control. In this test, the converter bridge was subjected to $430 \mathrm{kA}$ peak short current test. There is no deformation or damage to the structure, and the test results showed that the structural strength of the converter meets the design requirements. The test photo and the current profile is shown in Fig. 12.

DC line disconnector type test is realized in the pulse mode to verify mechanical stability and thermal stability under shock current conditions of $380 \mathrm{kA}$ peak current. The DC line disconnector is not deformed or damaged, and the test results showed that the designed disconnector meets

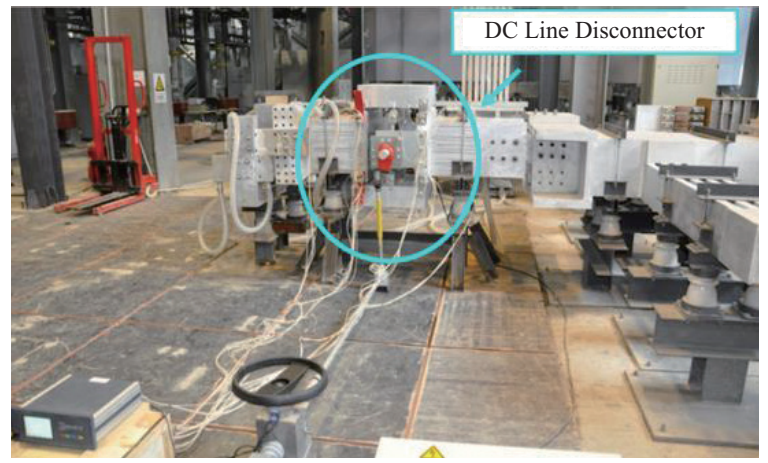

(a)

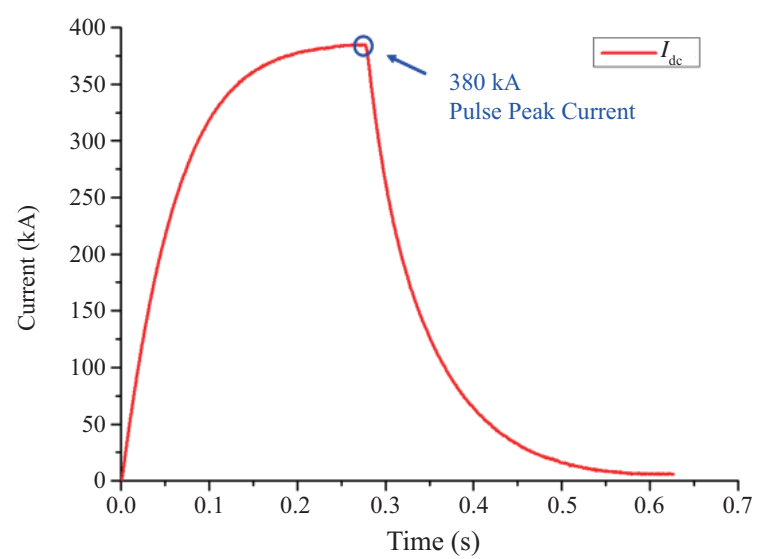

(b)

Fig. 13. DC Line Disconnector type test. (a) Test photo. (b) Test profile $\left(I_{\mathrm{dc}}\right.$ is the dc terminal current).

the design requirements. The test photo and the current profile is shown in Fig. 13.

DC busbar type test is realized in the steady state current mode to verify the thermal stability. The steady state current is $27.5 \mathrm{kA}$, the test continues until the bus temperature reaches equilibrium. The test results showed that design of the DC busbar meets the design requirements. The test photo and the current profile is shown in Fig. 14.

\section{Conclusion}

The DC high-power test facility is designed and constructed by ASIPP which aims to perform the test of ITER PF AC/ DC converter system and meets the future continuous upgrading needs of the modern industrial power system and scientific research. Certified by CNAS in May 2017, 15 test reports are accepted by 35 countries in the world. The steady-state current of DC high-power test facility is rated at $120 \mathrm{kA}$. The pulse peak current is $500 \mathrm{kA}$. The DC high-power test facility is developed into a high-power electrical professional test facility, which is capable of the type test and routine test of the components in industry, rail traffic and electric power. In this paper, the topology and the control of the DC high-power test facility are presented. Then the performance results from the experiments of 


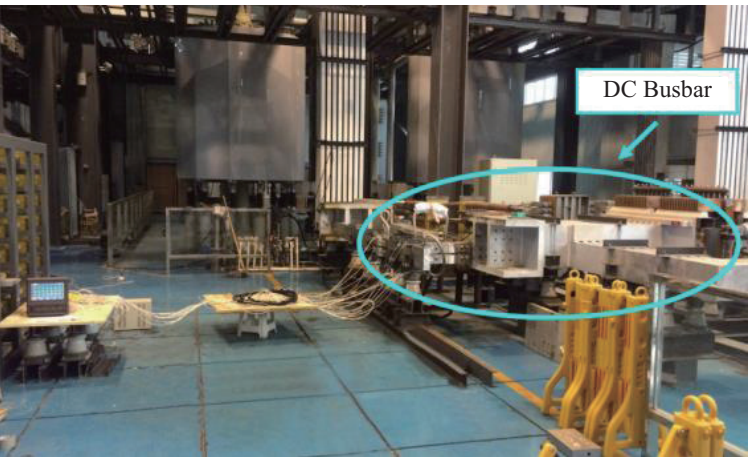

(a)

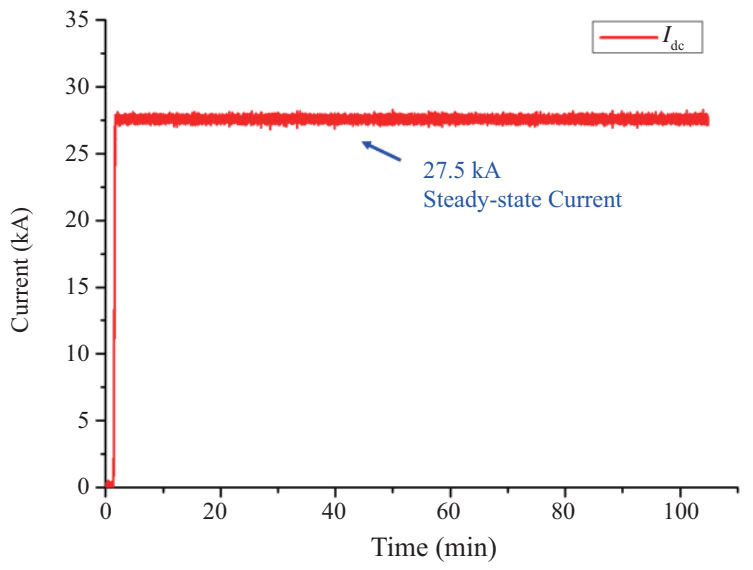

(b)

Fig. 14. DC Busbar type test. (a) Test photo. (b) Test profile ( $I_{\mathrm{d}}$ is the dc busbar current).

its testing capability are reported. The experiment results illustrated that the testing capability that $120 \mathrm{kA}$ steadystate continuous current and $500 \mathrm{kA}$ pulse current of DC high-power test facility is qualified.

\section{ACKNOWLEDGMENT}

The authors would like to thank all the members of ASIPP AC/DC converter team.

\section{REFERENCES}

[1] X. Chen et al., "Overview of CASHIPS High-Power Electrical Equipment Test Facility," 2018 IEEE 4th Southern Power Electronics Conference (SPEC), Singapore, Singapore, 2018, pp. $1-4$.

[2] A. Luchetta, G. Manduchi, C. Taliercio, A. Rigoni, and N. Pomaro, et al. "Overview of instrumentation and control in the neutral beam test facility",European Conference on Circuit Theory and Design (ECCTD), pp. 1-4, Sept. 2017.

[3] P. Fu et al., "Review and analysis of the AC/DC converter of ITER coil power supply," 2010 Twenty-Fifth Annual IEEE Applied Power Electronics Conference and Exposition (APEC), Palm Springs, CA, 2010, pp. 1810-1816.

[4] P. Fu,G. Gao, Z. Q. Song, L. W. Xu, and L. S. Huang et al., "Preliminary design of the poloidal field AC/DC converter system for the ITER coil power supply", Fusionence and Technology, vol.64, pp. 741-747, Mar 2013.
[5] J. Tao, I. Benfatto, J. K. Goff, A. Mankani, and F. Milani et al., "ITER coil power supply and distribution system", Fusion Engineering, Chicago, IL, USA, Octo. 2011.

[6] X. Q. Zhang, "Study on the test method of ITER poloidal field converter system," Ph.D. dissertation, University of Chinese Academy of Sciences, China, 2015 (in Chinese).

[7] J. C. Li, "R\&D of ITER PF AC/DC converter module," Ph.D. dissertation, University of Chinese Academy of Sciences, China, 2012 (in Chinese).

[8] L. Li, P. Ning, X. Wen, and D. Zhang, "A 1200V/200 A half-bridge power module based on SiIGBT/SiC MOSFET hybrid switch," CPSSTransactions on Power Electronics and Applications, vol. 3, no. 4, pp. 292-300, Dec. 2018.

[9] A. Q. Huang, Q. Zhu, L. Wang, and L. Zhang, "15kV SiC MOSFET: Anenabling technology formedium voltage solid state transformers," CPSS Transactions on Power Electronics and Applications, vol. 2, no. 2, pp.118-130, Jun. 2017.

[10] D. Rothmund, D. Bortis, and J. W. Kolar, "Highly compact isolated gate driver with ultrafastovercurrent protection for $10 \mathrm{kV}$ SiC MOSFETs," CPSS Transactions on Power Electronics and Applications, vol. 3, no. 4, pp. 278-291, Dec. 2018.

[11] X. J. Chen, "Research on key issues of modular designed superconducting coil AC/DC converter power supply," Ph.D. dissertation, University of Science and Technology of China, China, 2017 (in Chinese).

[12] C. Li, Z. Song, P. Fu, M. Zhang, and X. Q. Zhang, "Thermal design of high-power DC reactor for ITER poloidal field converter," Journal of Fusion Energy, vol. 33, no. 5, pp. 588-593, May 22, 2014.

[13] L. S. Huang and P. Fu, "Optimization design of control system of ITER high-voltage power converter," High Voltage Engineering, vol. 36 , no. 7 , July 31,2010 (in Chinese).

[14] X. Chen et al., "High power test facility $500 \mathrm{kA}$ pulse current sharing control," 2018 IEEE International Power Electronics and Application Conference and Exposition (PEAC), Shenzhen, 2018, pp. 1-4.

[15] S. Hu, Automatic Control Theory, Science Press, Beijing, 2007 (in Chinese)

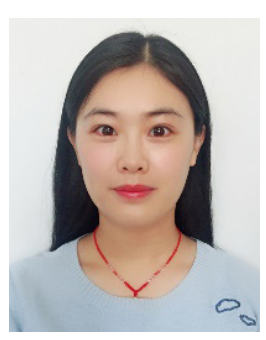

Xiaojiao Chen was born in Anhui, China, in 1989. She received the $\mathrm{Ph} . \mathrm{D}$. degree in nuclear science and engineering from the Chinese Academy of Sciences, Hefei, China, in 2017.

She is currently an Assistant Researcher with the Institute of Plasma Physics, Chinese Academy of Science. Her current research interests include the analysis of the operational performance of poloidal field converter system and the optimizing of their control systems.

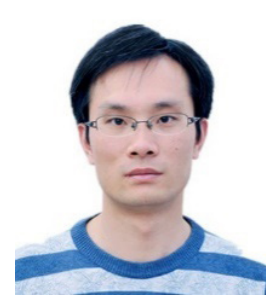

Liansheng Huang was born in Jiangxi, China, in 1983. He received the Ph.D. degree in nuclear science and engineering from the Chinese Academy of Sciences, Hefei, China, in 2010.

$\mathrm{He}$ is currently an Associate Professor with the International Thermonuclear Experimental Reactor Project, Institute of Plasma Physics, Chinese Academy of Sciences. His current research interests include power supplies and their control systems of fusion devices. 


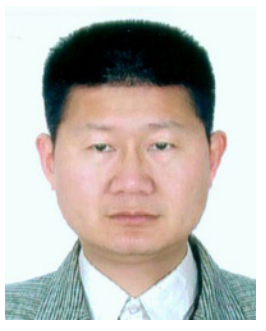

Peng Fu was born in Hubei, China, in 1962. He received the B.S. degree in electrical engineering from the Huazhong University of Science and Technology, Wuhan, China, in 1985, and the M.S. and $\mathrm{Ph} . \mathrm{D}$. degrees in electrical engineering from the Chinese Academy of Sciences, Hefei, China, in 1990 and 1997, respectively.

He is currently a Professor and a Manager of the International Thermonuclear Experimental Reactor Project, Institute of Plasma Physics, Chinese Academy of Sciences. His current research interests include power supplies and their control systems of fusion devices.

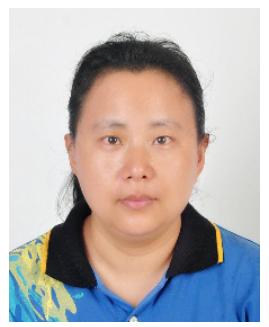

Ge Gao was born in Anhui, China, in 1975. She received the B.S. degree in electrical motor and automation from the Hefei University of Technology, Hefei, China, in 1996, and the Ph.D. degree in nuclear engineering from the Chinese Academy of Sciences, Hefei, in 2006.

She is currently a Professor with the International Thermonuclear Experimental Reactor Project, Institute of Plasma Physics, Chinese Academy of Sciences. Her current research interests include power supply systems of fusion devices.

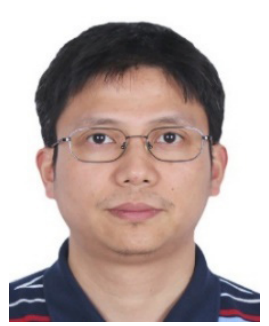

Zhiquan Song was born in Anhui, China, in 1975. He received the B.S. degree in power supply system and automation from Hefei University of Technology in 1999, and the Ph.D. degree in nuclear energy science and engineering from the Graduate University of Chinese Academy of Sciences in 2007.

$\mathrm{He}$ is currently a Senior Engineer of the International Thermonuclear Experimental Reactor project with the Institute of Plasma Physics, Chinese Academy of Sciences. His current research interests include coil power supply systems and quench protection breaker of fusion devices.

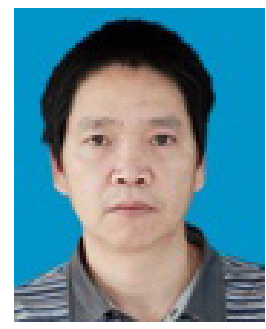

Liuwei Xu was born in Henan, China, in 1967. He received the B.S. degree in electrical engineering from the Hefei University of Technology, Hefei, China, in 1989, and the M.S. degree in nuclear energy science and engineering from the Chinese Academy of Sciences, Hefei, in 1999.

$\mathrm{He}$ is currently a Professor of the International Thermonuclear Experimental Reactor Project with the Institute of Plasma Physics, Chinese Academy of Sciences. His current research interests include magnet power supplies and reactive power compensation systems of fusion devices.

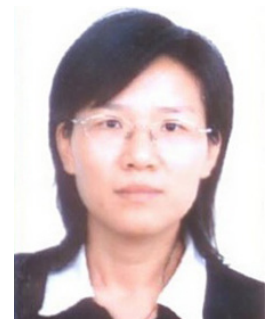

Shiying He was born in Anhui, China, in 1972. She received the B.S. degree in automation from the University of Shanghai for Science and Technology, Shanghai, China, in 1994.

She is currently a Senior Engineer with the International Thermonuclear Experimental Reactor Project, Institute of Plasma Physics, Chinese Academy of Sciences, Hefei, China. Her current research interests include power supply control systems of fusion devices.

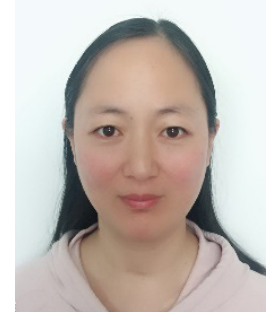

Xiuqing Zhang was born in Anhui, China, in 1980. She received the B.S. degree in electrical engineer and automation from Hefei University of Technology, Hefei, China, in 2005, and the Ph.D. degree in nuclear energy science and engineering from the Institute of Plasma Physics, Chinese Academy of Science, Beijing, China, in 2015. Her current research interests include integration and test of coil power supply system. 